\title{
POLYPROPYLENE/STARCH BLENDS. STUDY OF THERMAL AND MORPHOLOGICAL PROPERTIES
}

\author{
MÓNICA A. PÉREZ R*, BERNABÉ L. RIVAS Q*, SADDYS RODRÍGUEZ-LLAMAZARES**.
}

*Polymer Departament, Faculty of Chemistry Sciences, University of Concepción, Casilla 160-C, Concepción, Chile. Edmundo Larenas 129 Concepción- CHILE.
**Research Center of Advanced Polymers (CIPA), Conicyt-Regional R08C1002, Avda. Cordillera, Concepción, Chile

(Received: September 3, 2012 - Accepted: November 21, 2012)

\section{SUMMARY}

Polypropylene/starch blends were prepared using starch of different botanical source. The influence of starch type and starch content on thermal properties and morphology of polypropylene/starch blends was studied. Corn and potato starches were used as starch source. The starch content in the blends was 7 and 15 wt- $\%$. Characterization of PP and PP/starch blends by (DSC), (TGA), and (SEM) was carried out to obtain information on miscibility among PP and starch. The starch domains exhibited characteristic voids be due to thermal degradation.

Two types of $\mathrm{PP}, \mathrm{PP}_{1}$ poly(propylene-co-ethylene), random copolymer, and $\mathrm{PP}_{3}$ poly(propylene-co-ethylene), heterophasic copolymer were studied

Keywords: Polypropylene, starch, blends, characterization

\section{INTRODUCTION}

Blends are a mixture of two or more polymers obtained by melting or in solution. Its objective is the preparation of a material that posses the combination of properties of their components, not compassable by separated. The development of a blend with an adequate behavior, especially with respect to their mechanical and physical properties, depends on the interfacial adhesion among the phases. A compatible blend is that in which the dispersed or minority phase is found homogeneously distributed in the matrix or majority phase and in which the adhesion among the same is strong. In this type of blends, a force applied is transmitted among the components of the phases (1).

Polypropylene (PP), a synthetic polymer is an economical material that offers a combination of outstanding physical, mechanical, thermal, chemical properties that are not found in any other thermoplastic polymer (2)

The great number of polyolefinic products has caused harmful consequences to the nature due to the low degradation rates reached by the traditional polyolefins, e.g. low-density polyethylene (LDPE) and isotactic polypropylene (iPP).

By this way, researchers have studied the incorporation of biodegradable polymers, such as the starch, to the traditional polyolefins, which is justified by the presence of hydrolyzable groups in the natural polymer that are able to induce the biodegradation of the polyolefins (3-5).

Ramis et al. (6) evaluated the biodegradability of iPP/starch blends under simulated soil and observed the materials decomposition under nitrogen and oxygen atmosphere, by different mechanisms of degradation. The biodegradation affected the starch but not the iPP matrix.

When dealing with starch-derivative materials, this last can present a thermoplastic characteristic (commonly called thermoplastic starch or TPS) when incorporating glycerin to it, acting as a plasticizer (7).Moreover, the use of glycerin, as described by Carvalho (7) can increase the fragmentation rate of the material (morphological structure), obtaining though materials with many different characteristics just by varying the amount of glycerin on the starch.

In general, it is said that in order to let the polyolefins more susceptible to degradation, some kind of modification is necessary, such as modifications on the crystallinity degree (8), chemical degradation and reduction on the molar mass of polymers to create short molecules that are capable of being absorbed by microorganisms (9).

The inclusion of such materials allows products traditionally produced from non-renewable and environmentally persistent petroleum-based materials, to be produced from materials made from renewable resources which may also provide a degree of degradability to the final product. Starch, in particular, has been used since the 1970s as a filler in plastics (10) and has recently been plasticized and extruded with traditional plastics (11) used as a baked foam for thin walled applications (12), and used as packaging foams (13). Dry granular starch and baked starch, which is pressed and molded, have limited processability and can be used in only a limited range of applications. Plasticized starch, however, is more versatile and can be blended with various polymeric materials for numerous applications.

Starch is an abundant, naturally occurring polysaccharide that is obtained from various plant sources, such as corn, potato, rice, and cassava [14]. Starch is a semi-crystalline polymer comprised of glucose monomer units. its granular form is comprised of linear amylose or branched amylopectin macromolecules with amylose content of ranging from $20-30 \%$ (see Scheme 1). Dry granular starch, by itself, cannot be processed like a plastic; however, it can be heated and blended with several different small polar molecules (water, glycerol) or polar oligomers (polyols), giving a thermoplastic material, generally called (PLS). This process, known as gelatinization, breaks up the granular structure of starch by disrupting hydrogen bonding between adjacent glucose molecules and essentially destroys its crystallinity [15].

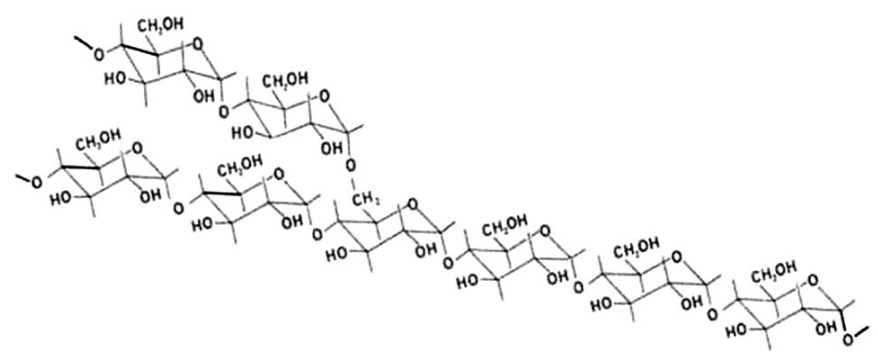

Scheme 1. Starch structure

On the other hand, St. Pierre et al. (16) studied the mechanical properties of low density polyethylene (LDPE)/thermoplastic starch blends and of linear low density polyethylene (LLDPE)/thermoplastic starch. These compounds had better processability and mechanical properties than those with the untreated starch. Nevertheless, for high percentages of thermoplastic starch, there was a drastic reduction in the mechanical properties. Therefore, Matzinos et al. (17) studied the effect of incorporating low density polyethylene functionalized with maleic anhydride (LDPE- $g$-MAH) as a compatibilizer with $30 \%$ of natural corn starch, emphasizing that the biodegradation of the compatible blends was only slightly lower than that of the non compatible compounds

The aim of this study was to determine the morphological and thermal properties of $\mathrm{PP} /$ starch blends, using starches of different botanical sources. The starch content in the blends ranged from 7 to $15 \mathrm{wt}-\%$.

\section{EXPERIIMENTAL PART}

2.1 Materials

PP poly(propylene-co-ethylene); random copolymer (MFR 2,16 $\mathrm{kg} / 230^{\circ} \mathrm{C}$ ): $8.5 \mathrm{~g} / 10 \mathrm{~min}, \mathrm{PP}_{3}\left(\mathrm{MFR} 2,16 \mathrm{~kg} / 230^{\circ} \mathrm{C}\right.$ ), poly(propylene-coethylene), heterophasic copolymer $12 \mathrm{~g} / 10 \mathrm{~min}$, from PETROQUIM S.A. Glycerine adquired Sigma- Aldrich.

The different types of starches: corn starch (CS) and potato starch (PS) were obtained Sigma-Aldrich.

1.2 Melt Processing

$\mathrm{PP}_{1} /$ starch and $\mathrm{PP}_{3} /$ starch blends were obtained in a twin-screw co-rotating extruder (Haake H-25, model Rheomex PTW 16/25, L/D 1/4 25) operating at $80 \mathrm{rpm}$. The temperature conditions, 150 and $170^{\circ} \mathrm{C}$ for preparation and 
processing of blends were chosen to minimize possible degradation of the organic modifier and the matrix.

The PP/starch blends were prepared as described in Table 1, using 7 and $15 \%$ wt CS and PS.

Table 1. Experimental conditions of $\mathrm{PP} /$ starch blends

\begin{tabular}{|c|c|c|}
\hline Experimental conditions & $\mathrm{PP}_{1}$ & $\mathrm{PP}_{3}$ \\
\hline Mixing temperature $\left({ }^{\circ} \mathrm{C}\right)$ & 150 & 180 \\
\hline Mixing time $(\mathrm{min})$ & 7 & 5 \\
\hline Mixing speed $(\mathrm{rpm})$ & 80 & 80 \\
\hline Glycerine concentration $(\%$ en mass) & 2 & 2 \\
\hline
\end{tabular}

From the prepared PP blends, the films were obtained by compression heating the polymer up to $190^{\circ} \mathrm{C}$, maintaining for $2 \mathrm{~min}$ to obtain the complete melting of the pellets, and a pressure of 6 pounds was applied for $3 \mathrm{~min}$.

\section{$1.3 \mathrm{PP} /$ starch characterization}

Differential scanning calorimetry (DSC) measurements were made on DSC Q200 TA Instrument. All measurements were carried out under nitrogen atmosphere. The samples were heated from 50 to $200^{\circ} \mathrm{C}$ at a heating and cooling rate of $5^{\circ} \mathrm{C} / \mathrm{min}$. The measurements were accomplished during the second heating and cooling cycle.

Thermogravimetric analyses were carried out on a T.A model QA-50 to obtain the inorganic and organic residue, and the clays' descomposition profile, and PP blends. The samples ( $10.0 \mathrm{mg}$ in film form) were heated from 25 to $600^{\circ} \mathrm{C}$ at heating rate of $10^{\circ} \mathrm{C} / \mathrm{min}$ under nitrogen flow.

The morphologies of the PP/starch blends were examined by JEOLJSM $6380 \mathrm{LV}$ scanning electron microscopy. The fractured surface of blends were coated with a gold film of ca. $50 \mathrm{~nm}$ and the images were taken at an accelerating potential of $20 \mathrm{kV}$.

\section{RESULTS AND DISCUSSION}

3.1.1. $\mathrm{PP}$, blends characterization for DSC

The figure 1 shows the DSC thermograms of neat $\mathrm{PP}_{1}$ and $\mathrm{PP} / \mathrm{CS}$ blend, and Figure 2 shows pure $\mathrm{PP}_{1}$ and $\mathrm{PP}_{1} / \mathrm{PS}$ blend. The peak around $150^{\circ} \mathrm{C}$, corresponds to melting temperature of $\mathrm{PP}_{1}$ in both thermograms.

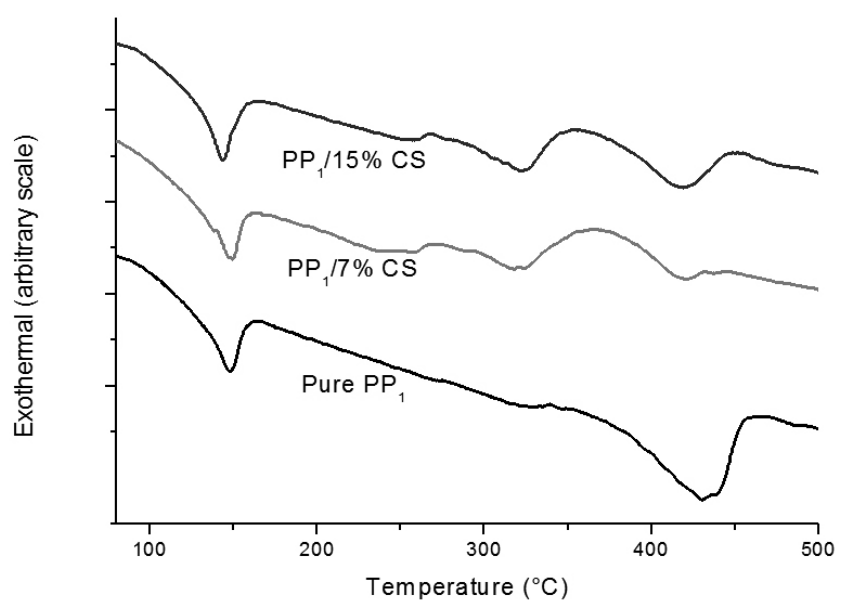

Figure 1: DSC thermograms for pure $\mathrm{PP}_{1}$ compared with $\mathrm{PP}_{1} / \mathrm{CS}$ blend.

The peak above $400^{\circ} \mathrm{C}$ in pure $\mathrm{PP}$ and $\mathrm{PP} / \mathrm{CS}$ (see Figure 1), and PP/PS in figure 2 blend is due to the decomposition of $\mathrm{PP}_{1}$ and $\mathrm{PP}_{1} / \mathrm{CS}$ and $\mathrm{PP} / \mathrm{PS}$ blend, respectively. In both figures, the thermograms show the presence of an additional melting peak around $300-350^{\circ} \mathrm{C}$. This peak is not present in pure $\mathrm{PP}_{1}$. It is due to the presence of an amylose content as well as corn and potate starches increase in the blend. This increase of amylose content that produce greater dispersion of CS and PS in PP increases the miscibility, as showed by Simmons et al (18).

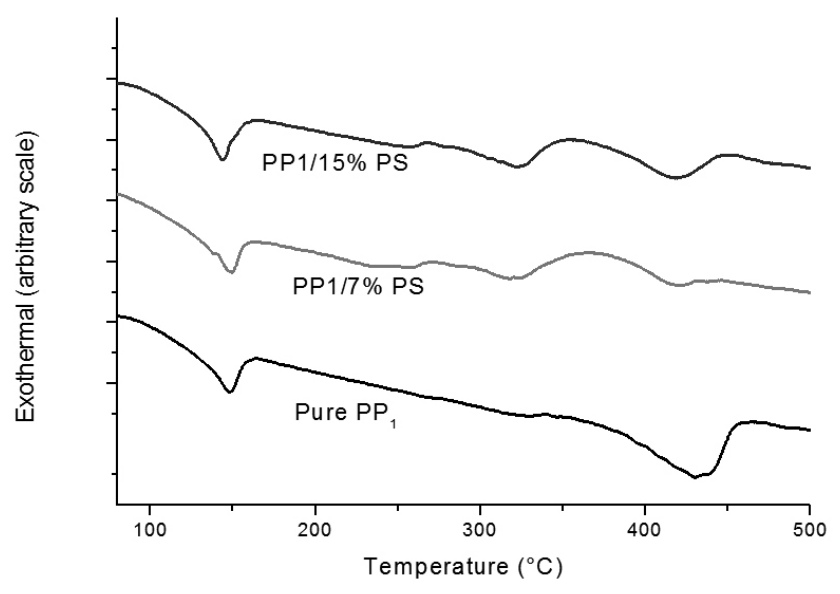

Figure 2: DSC thermograms for pure $\mathrm{PP}_{1}$ compared with $\mathrm{PP}_{1} / \mathrm{PS}$ blend.

The peak between $300-350^{\circ} \mathrm{C}$ is clearly observed with $7 \%$ corn starch (CS) (see figure 1) instead with a 7\% potato starch (PS) is not, it is due the content is higher in amylose corn starch ( $\sim 29 \%)$ compared to potato starch ( 21\%) (19).

3.1.2. $\mathrm{PP}_{3}$ blends characterization for DSC

The Figure 3 shows the DSC thermograms of pure $\mathrm{PP}_{3}$ and $\mathrm{PP}_{3} / \mathrm{CS}$ blend, and Figure 4 shows pure $\mathrm{PP}_{3}$ and $\mathrm{PP}_{3} / \mathrm{PS}$. The peak $\sim$ at $170^{\circ} \mathrm{C}$ corresponds to melting temperature of $\mathrm{PP}_{3}$ (see Figures 3 and 4).

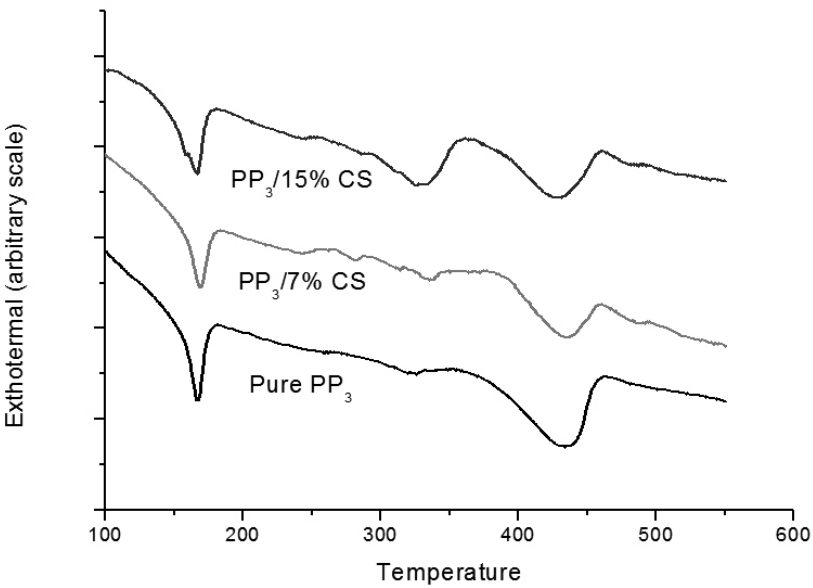

Figure 3: DSC thermograms for pure $\mathrm{PP}_{3}$ compared with $\mathrm{PP}_{3} / \mathrm{CS}$ blend. Figure 3 shows at $\sim 450^{\circ} \mathrm{C}$ the decomposition temperature of neat $\mathrm{PP}_{3}$ and $\mathrm{PP}_{3} / \mathrm{CS}$ blends. The thermograms show the presence of an additional melting peak which ocurred at $300-350^{\circ} \mathrm{C}$. This peak, wich was not present in pure $\mathrm{PP}_{3}$, is due to the presence of amylose. The peak intensity between $300-350$ ${ }^{\circ} \mathrm{C}$ increases with the amylose content, and increases the miscibility of blend. 


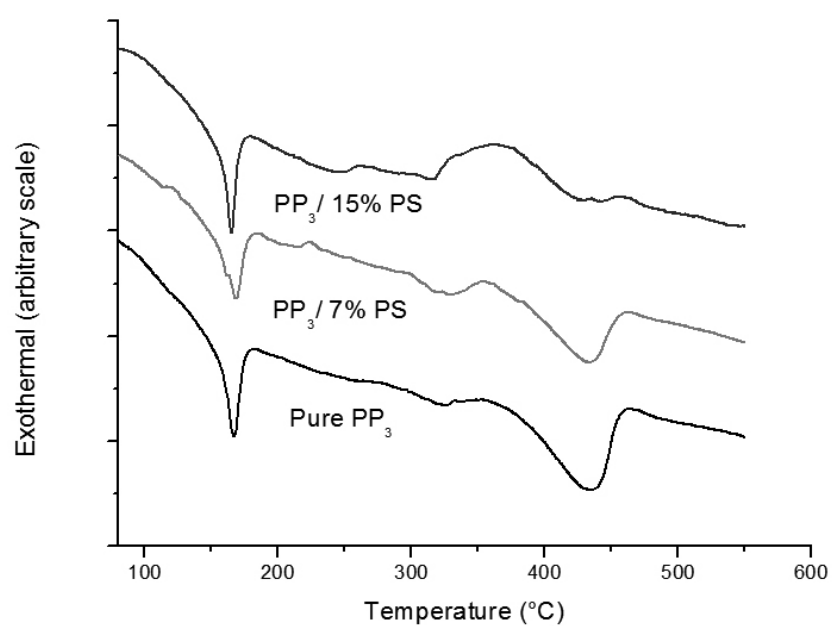

Figure 4: DSC thermograms for neat $\mathrm{PP}_{3}$ compared with $\mathrm{PP}_{3} / \mathrm{PS}$ blend

Figure 4 shows between $300-350^{\circ} \mathrm{C}$ an additional melting peak. This peak was not present in pure $\mathrm{PP}_{3}$, is due to the presence of amylose content. In this case, with $15 \%$ CS is not yet clearly see the peak corresponding to amylose, probably due to the potato starch amylose has a lower concentration $(\sim 21 \mathrm{wt} \%)$

3.1.3. $\mathrm{PP}_{1}$ and $\mathrm{PP}_{3}$ blends characterization for TGA.

Figure 5 shows decomposition profile of $\mathrm{PP}_{1}$ and $\mathrm{PP}_{1} / \mathrm{CS}$ blend. Thermal stability decreases in the presence of a mixture compared with neat PP

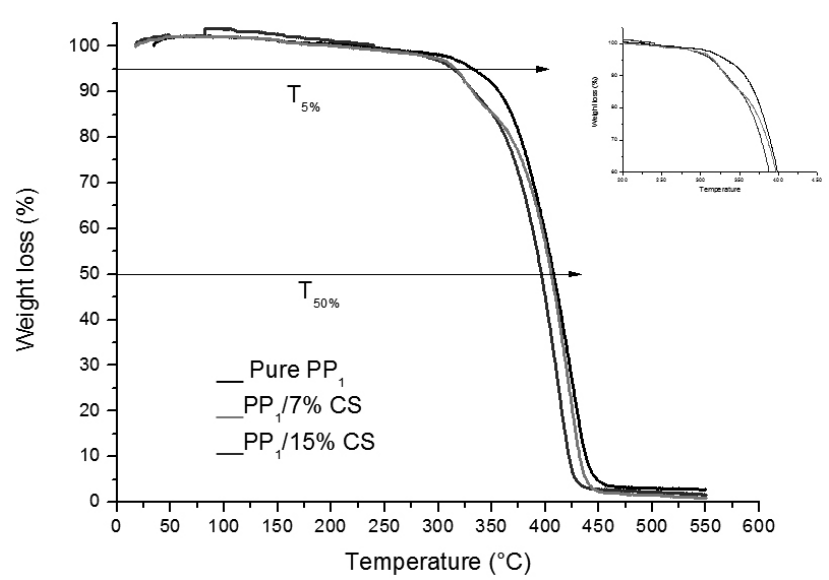

Figure 5. TGA curves of $\mathrm{PP}_{1}$ and $\mathrm{PP} / \mathrm{CS}$ blend

The decomposition temperatures decrease with increasing the starch content of the blends

Table 2 shows the $\mathrm{T}_{5 \%}$ (temperature at which $5 \%$ of weight loss ocurrs) and $\mathrm{T}_{50 \%}$ (temperature at which $50 \%$ of weight loss ocurrs) for $\mathrm{PP}_{1}$ and $\mathrm{PP}_{3}$ and their blends, respectively.

Table 2. Thermal properties of PP/starch blends.

\begin{tabular}{|c|c|c|}
\hline Sample & $\mathrm{T}_{(-5 \%)}$ & $\mathrm{T}_{50 \%}$ \\
\hline $\mathbf{P P}_{\mathbf{1}}$ & $\mathbf{3 3 4}$ & $\mathbf{4 0 8}$ \\
\hline $\mathrm{PP}_{1} / 7 \% \mathrm{CS}$ & 317 & 406 \\
\hline $\mathrm{PP}_{1} / 15 \% \mathrm{CS}$ & 311 & 397 \\
\hline $\mathrm{PP}_{1} / 7 \% \mathrm{PS}$ & 320 & 404 \\
\hline $\mathrm{PP}_{1} / 15 \% \mathrm{PS}$ & 317 & 396 \\
\hline $\mathbf{P P}_{3}$ & $\mathbf{3 3 6}$ & $\mathbf{4 1 0}$ \\
\hline $\mathrm{PP}_{3} / 7 \% \mathrm{CS}$ & 317 & 403 \\
\hline $\mathrm{PP}_{3} / 15 \% \mathrm{CS}$ & 314 & 394 \\
\hline $\mathrm{PP}_{3} / 7 \% \mathrm{PS}$ & 334 & 407 \\
\hline $\mathrm{PP}_{3} / 15 \% \mathrm{PS}$ & 322 & 392 \\
\hline
\end{tabular}

Table 2 shows that the initial decomposition temperature $\left(\mathrm{T}_{-50}\right)$ of $\mathrm{PP}_{1}$ is $334{ }^{\circ} \mathrm{C}$. In the blends $\mathrm{PP}_{1} / 7 \% \mathrm{CS}$ and $\mathrm{PP}_{1} / 15 \% \mathrm{CS}$ initial decomposition temperatures decrease with the increase of corn starch in the blend. This effect is due to amylose content

The same occurs when $\mathrm{T}_{50 \%}$ decomposition temperature decreases by increasing the starch content in the blend. The increase of amylose content that produces greater dispersion de CS and PS in PP increases the miscibility (19).

In the case of $\mathrm{PP}_{3} \mathrm{~T}_{-5 \%}$ and $\mathrm{T}_{50 \%}$, the decomposition temperature decreases by less than $\mathrm{PP}_{1}$ with increased starch content in the blends. This is probably due to the structure of $\mathrm{PP}_{1}$ and $\mathrm{PP}_{3}$. $\mathrm{PP}_{1}$ poly(propylene-co-ethylene); random copolymer and $\mathrm{PP}_{3,}$ poly(propylene-co-ethylene), heterophasic copolymer

3.1.4. $\mathrm{PP}_{3}$ blends characterization by SEM.

Figure $\left.\left.6^{3} \mathrm{~A}\right), \mathrm{B}\right), \mathrm{C}$ ), and d) show the SEM microphotography for $\mathrm{PP}_{3}$, $\mathrm{PP}_{3} / 7 \% \mathrm{CS}, \mathrm{PP} / 15 \% \mathrm{CS}$. Micron scale phase separation was determined by an examination of blend with SEM. The CS does not undergo complete melting and remain dispersed in the continuos $\mathrm{PP}_{3}$. The distribution is significantly higher in $15 \%$ CS. Due to the fact that de CS content is the highest compared with other blends

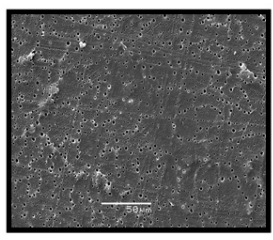

A

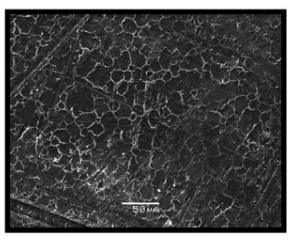

B

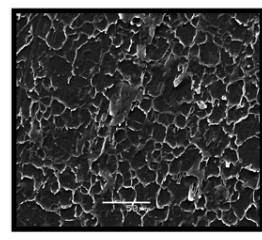

C CS

Figure 6: $\mathrm{SEM}$ images of $\mathrm{PP}_{3}$ blends. $\mathrm{A}: \mathrm{PP}_{3}, \mathrm{~B}: \mathrm{PP}_{3} / 7 \% \mathrm{CS}, \mathrm{C}: \mathrm{PP}_{3} / 15 \%$

\section{CONCLUSIONS}

From the thermodegradative studies of the PP/CS and PP/PS blends, it can be concluded that the CS and PS content induces a retardant effect on the degradative process of the PP, since it increases the initial decomposition temperature of the blend, acting like an anti-oxidant agent.

The presence of an amylose content as well as corn and potate starches increase in the blend. This increase of amylose content produced a greater dispersion of CS and PS in PP increases the miscibility. It was corroborated by DSC, TGA, and SEM

$\mathrm{PP} / \mathrm{CS}$ blends have lower decomposition temperatures of PP/PS because corn starch has a higher content of amylose than that potato starch.

\section{ACKNOWLEDGEMENTS}

The authors thank the DIUC project (Grant No D05110383), CIPA (Centro de Investigación de Polímeros Avanzados). The commercial polypropylene samples provided by PETROQUIM S.A., Chile.

\section{REFERENCES}

1. R. Mani, J. Tang, M. Bhattacharya, Macromol. Rapid Commun, 19, 283 (1998).

2. M Pérez, B. Rivas, S. Rodríguez, A. Maldonado, C. Venegas, J. Chil. Chem. Soc., 55, 4, 440 (2010).

3. D. Zuchowska; D. Hlavatá; R. Steller; W. Adamiak; W. Meissner Polym. Degrad. Stab. 64, 339, (1999).

4. P. Shah; S. Bandopadhyay; J. R. Bellare Polym. Degrad. Stab. 47, 165, (1995).

5. D. Zuchowska; R. Steller; W. Meissner Polym. Degrad. Stab. 60, 471, (1995)

6. X. Ramis; A. Cadenato; J. M. Salla; J. M. Morancho; A. Vallés; L. Contat; A. Ribes Polym.Degrad. Stab. 86, 483, (2004)

7. C. L. Carvalho, Master Thesis, Universidade São Francisco, (2005).

8. H. A. A. El-Rehim Photobiol. A: Chem. 163, 547, (2004).

9. D. Bikiaris Polym. Degrad. Stab. 57, 313, (1997).

10. Griffin, G.J.L., British Patent 1,586, 344, in British Patent. (1973).

11. Bikiaris, D. and C. Panayiotou. J. Appl. Polym. Sci, 70(8), 1503, (1998)

12. Shogren, R.L., et al., Polymer, 39(25), 6649, (1998) 
13. . Fang, Q. and M.A. Hanna, Industrial Crops and Products, 13(3), 219, (2001)

14. Eliasson, A.-C., ed. Starch in food: Structure, function and applications. Woodhead Publishing. 384, (2004)

15. Shogren, R.L., Effect of moisture and various plasticizers on the mechanical properties of extruded starch, in Biodegradable Polymers and Packaging, Editors. Technomic Publication. p. 141-150. (1993)
16. St. Pierre, N., Favis, B.D. Ramsay, J.A., Vergoogt, H. Polymer, 38: 647$656,(1997)$

17. Matzinos, P., Bikiaris, D., Kokkou, S., Panayiotou C. J. Appl. Polym. Sci., 79: 2548, (2001)

18. Simmons S., Thomas L.E, J. Appl.Polym. Sci., 58, 2259 (1995).

19. Hernández M, Torruco Juan, Chel Luis, Betancur David. Cienc. Tecnol. Aliment, 28, 718 (2008). 